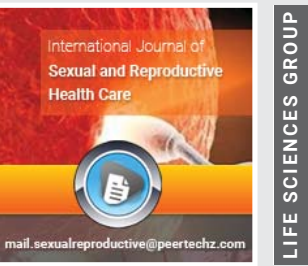

\title{
Knowledge and perception of community health volunteers of family planning services towards COVID-19 Disease
}

\author{
Jennifer Anyanti, Anthony Nwala, Chinedu Edward \\ Onyezobi*, Emmanuel Ekerrete Udoh, Hasiya Ahmadu and \\ Raymond Songo
}

Society for Family Health, Abuja, Nigeria

Received: 07 December, 2020

Accepted: 28 December, 2020

Published: 31 December, 2020

*Corresponding author: Chinedu Edward Onyezobi, Society for Family Health, Abuja, Nigeria, Email: conyezobi@sfhnigeria.org,chiward007@yahoo.com

https://www. peertechz.com

Check for updates

\begin{abstract}
Background: As at the end of August 2020, the coronavirus disease outbreak has hit more than 50,000 across all the 36 states of Nigeria. Whilst the federal government declared contraception an essential service that can continue to be assessed from health facilities, the fear of contracting the disease and stigma associated to facility visits limit the visit of women to health facilities. Given this issue, the role of community health volunteers trained to provide family planning products and services to women in communities becomes very important. A poor understanding of the disease and its transmission routes among these health volunteers may affect continuous uptake of family planning services and result to spread of the infection in communities.
\end{abstract} Nigeria.

Objective: This study aimed to assess the knowledge and perception of community health volunteers of family planning services towards COVID-19 disease in

Methods: A cross-sectional, web-based study was conducted among community health volunteers of family planning services about COVID-19. A 19-item survey instrument was developed and distributed randomly among the volunteers using Survey Solutions weblink. The questionnaire requires between 5 to 10 minutes to complete. A chi-square test was used to investigate the level of association among variables, with significance set at $95 \% \mathrm{Cl}$. The analysis of variance and independent $\mathrm{t}$-test was used to test significant difference among socio-demographic variables with respect to knowledge and perception scores. Significance is also set at $95 \% \mathrm{Cl}$.

Results: The questionnaire was completed by 366 volunteers out of 832 volunteers offering family planning services in communities. The average age of the respondents was $31.63 \pm 7.60$ years with majority within the age band of $28-37$ years, $288(78.7 \%)$ were females, $200(54.6 \%)$ were married, $304(83.1 \%)$ have tertiary educational qualification and $131(35.8 \%)$ were $\mathrm{CHEWs}, 30(8.2 \%)$ were Nurses. Most participant $344(82 \%)$ had a good knowledge of the disease and the average knowledge score was $10.40 \pm 1.46$ out of a total score of 12 . Majority also had a positive (right) perception towards COVID-19 disease 331(90.4\%) and the average perception score was $27.77 \pm 3.22$ out of a total of 35 score. There is a positive correlation $\left(r=0.212^{\star \star}, p=0.000\right)$ between knowledge and perception towards COVID-19 disease.

Conclusions: As the increasing number of COVID-19 cases continue to disrupt continuous uptake of family planning services, it is essential to improve the knowledge and perception of the community health volunteers. This improvement in knowledge and perception will ensure adequate precautions are taken to avoid the spread of the disease in communities. Educational Interventions are obviously needed to reach all healthcare including those offering services in communities.

\section{Introduction}

The COVID-19 disease is a huge threat to humanity in the world. It is an extremely expanding pandemic caused by novel human coronaviruses, which are large family of viruses that causes illness ranging from common cold to more severe diseases such as Middle East Respiratory Syndrome (MERSCOV) and Severe Acute Respiratory Syndone (SARS-COV) [1]. Coronaviruses are transmitted between animals and people. Recent studies have shown that SAR-CoV was transmitted from civet cats to humans and MERS-CoV from dromedary camels to humans. Common signs of infection include 
respiratory symptoms, fever, cough, shortness of breath and breathing difficulties. In more severe cases, infection can cause pneumonia, severe acute respiratory syndrome, kidney failure and even death. Standard recommendations to prevent infection spread include regular hand washing, covering mouth and nose when coughing and sneezing, thoroughly cooking meat and eggs. Avoid close contact with anyone showing symptoms of respiratory illness such as coughing and sneezing [2].

The COVID-19 disease was first announced in December 2019 among patients with viral pneumonia in one of emerging commercial cities in China called Wuhan [3]. Due to the rapid spread of this highly transmitted virus, WHO declared it as a "public emergency of International concern" on January 30,2020 . Later, due to the continual rise in the number of affected countries, cases, and fatalities, WHO declared COVID-19 as a global pandemic on 11 March 2020 [3]. As of 22 September 2020, more than 31.4 million cases have been reported across 188 countries and territories with more than 966,000 deaths; more than $\mathbf{2 1 . 5}$ million people have recovered. According to statistics from Nigeria Centre for Disease Control (NCDC), as at the end of August 2020, Nigeria have recorded more than 50000 confirmed cases of COVID-19, with 1100 death cases and more than 40000 recovered cases [4].

The disease has wrecked the lifestyle, daily route, business, and education system in the world [5]. In Nigeria, the education system was hugely affected by the pandemic as most schools were instructed to take their classes online. Delivering quality lectures to students online was very tough for teachers because most have not been effectively trained on how to use the various online platforms. Additionally, the teachers who are specialized in conventional teaching found it more difficult to cope with online methods [5]. During the lockdown some parents were forced to procure laptops, android phones, television cables and other means of ICT, this is to ensure their wards move with the new innovative of the online classes at various levels designed for teachers to reach out to their students. Most of the developing private schools in Nigeria could not afford the payment of their staffs during the period of lockdown because students are not in school, some have not paid the school levies before the emergence of the pandemic leading to school proprietors not having access to inflow of income to welfare their staffs working in their respective schools, in fact there is fear of whether private some schools in Nigeria will be able to survive and keep existing after the pandemic lockdown. The pandemic has also affected Nigeria's economy and citizens to a grave extent. With oil exports reported at 18-year low and job losses mounting, COVID-19 has destroyed whatever sense of progress Nigeria experienced since its last recession. With the support of the U.S International Affairs Budget, and with further foreign aid, Nigeria can hope for drastic changes in their job rates and oil exports.

The recent study on psychological distress experiences of Nigerians during Covid-19 pandemic; the gender difference, revealed that the overall prevalence of insomnia among the general public was $15 \%$ ( $4.75 \%$ severe insomnia and $10.3 \%$ moderate insomnia), a little less than a quarter (23\%) indicated experience of moderate depression to severe depression and a quarter $(25 \%)$ of the population indicated experiencing symptoms of severe posttraumatic stress and $18.1 \%$ indicated experiencing symptoms of clinical posttraumatic stress [6].

Whilst the Nigerian government has declared contraception an essential service that can continue to be accessed from health facilities, awareness of this is low and restrictions on travels and transport make access difficult. In addition, the fear of contracting COVID-19 and stigma associated to facility visits limits the visit of women to health facilities. It is also possible that the health facilities themselves could become overburdened with COVID-19 cases. Given these issues, the role of community health volunteers who make available family planning products and services to women in their communities is very important. A poor understanding of the disease and its transmission routes among these health volunteers may affect continuous uptake of family planning services and result to spread of the infection in communities. The purpose of this study is to assess the knowledge and perception of COVID-19 among community health volunteer offering family planning products and services to women in communities.

\section{Methods}

This cross-sectional survey was conducted from $21^{\text {st }}$ to $27^{\text {th }}$ October 2020. The survey was conducted among communitybased distribution agents working with Society for Family Health to drive uptake of DMPA-SC and self-injection among women of reproductive age in communities. These communities are in Adamawa, Gombe, Taraba, Kaduna, Kano, Katsina, Benue, Akwa Ibom and Edo states. Our sample consist of those who have been trained on administration of the DMPA-SC, self-injection contraception method and COVID-19 guidelines. Because it was not feasible to conduct in-person interviews with the community health volunteers during this period of COVID-19, we decided to collect the data online. The questionnaire was designed on Survey Solution, a data collection application which supports Computer Aided Web Interviews (CAWI) [7]. The application allows self-enumeration on web application interface i.e. respondents can fill out interviews in the browser without the support of an interviewer. A weblink was generated from the Survey Solution Application and was shared with all the community health volunteers via their WhatsApp Group. Participation in the survey was made voluntary. Those who confirmed their willingness to participate were directed to complete the self-report questionnaire.

\section{Sample size calculation}

To ensure adequate representative measurement we used the Daniel WW, 1999 formulae for measuring the prevalence of the learning outcome. Using the sample size calculation for prevalence studies formula with finite population (the sample size ( $\mathrm{n}^{\prime}$ ) will be thus computed [8].

$$
\mathrm{n}^{\prime}=\frac{\mathrm{NZ}^{2} \mathrm{P}(1-\mathrm{P})}{\mathrm{d}^{2}(\mathrm{~N}-1)+\mathrm{Z}^{2} \mathrm{P}(1-\mathrm{P})}
$$

Where: 


\section{$\mathrm{n}^{\prime}=$ Sample size with finite population}

$\mathrm{N}=$ Population size (the number of community-based distributor agents) $\mathrm{N}=832$ Agents

$\mathrm{Z}=\mathrm{Z}$ statistics for a level of confidence (The standard normal deviation at the required confidence level $=1.96$ )

$\mathrm{P}=$ Expected proportion. Since the proportion is unknown $50 \%$ will be used. Thus $\mathrm{P}=0.5$

$d=$ Level of Precision (error reduction) set at $5 \%$. (Thus $d=$ $0.05)$

$$
\mathrm{n}^{\prime}=\frac{832 \times 1.96^{2} \times 0.5 \times 0.5}{\left(0.05^{2} \times 832\right)+\left(1.96^{2} \times 0.5 \times 0.5\right)}
$$

$n^{\prime}=262 * 1.4($ Design effect $)=366$.

\section{Data collection instrument}

The structured questionnaire was broken into two sections - Demographics, and Knowledge and Perception. The demographic variables include age, gender, marital status, education, state, and local government areas. The knowledge questions were adopted from the study done in China by BaoLiang Zhong to assess Knowledge, attitudes, and practices towards COVID-19 among Chinese residents during the rapid rise period of the COVID-19 outbreak [9]. The questionnaire had 12 questions: 4 regarding clinical presentations (K1-K4), 3 regarding transmission routes $\left(\mathrm{K}_{5}-\mathrm{K}_{7}\right)$, and 5 regarding prevention and control (K8-K12) of COVID-19. These questions were answered on a true/false basis with an additional "I don't know" option. A correct answer was assigned 1 point and an incorrect/unknown answer was assigned 0 points. The total knowledge score is between the range of 0 to 12, with a higher score denoting a better knowledge of COVID-19. A 4-scale approach was adopted to categorize the overall knowledge into "Very Good, "Good", Fair" and "Poor. Participants who scored between 0-3 were assigned "Poor Knowledge", between 4-6 score were "Fair Knowledge",7-9 score were assigned "Good Knowledge" and 9-12 were "Excellent Knowledge". The perception questions were asked using Likert scale and there are 7 questions in this section. The maximum and minimum score for a Likert scale is 5 and 0 respectively, so the total perception score was between the range of 7 to 35 with a higher score depicting right perception towards COVID-19 disease [10].

\section{Data analysis}

The data analysis was done using SPSS version 25.0. Both descriptive and inferential statistic were employed to bring out insights from the study. The descriptive (percent and counts) was used to explain our findings from the demography, knowledge, and perception questions. A chi-square test was used to investigate the level of association among variables, with significance set at $95 \% \mathrm{CI}$. The analysis of variance and independent $\mathrm{t}$-test was used to test significant difference among socio-demographic variables with respect to knowledge and perception scores. Significance is also set at $95 \%$ CI.

\section{Results}

A total of 366 completed questionnaires were analysed in this study. The average age of the respondents was 31.63 \pm 7.60 years with majority within the age band of $28-37$ years, $165(45.1 \%)$. Majority of the respondents were females $288(78.7 \%)$ while the males were $78(21.3 \%)$. More than half of the respondents were married $200(54.6 \%)$ while those who are single were $154(42.1 \%)$. Great number of the participants has attained tertiary education $304(83.1 \%)$ while those with secondary education were $60(16.4 \%)$. At least 2 in every 5 respondents have medical background - 131(35.8 \%) were CHEWs,30(8.2\%) were Nurses while $2(0.5 \%)$ were Doctors. More than half of the respondents were those without medical background 203(55.5\%). The average period of experience by the participants as society for family health CBDA is $9.77 \pm 7.42$ months.

Majority of the respondents had a very good knowledge of COVID-19 disease, they constitute more than ninety percent of the participants; the average knowledge score is $10.40 \pm$ 1.46. Those with good knowledge of clinical presentation of COVID-19 was 332(90.7\%), good knowledge of transmission route was 333(91.0\%) and good knowledge of prevention and control was 349 (95.3\%). As shown in the Appendix, showing the association between socio-demographic characteristics and knowledge on covid-19 disease. There was no significant difference in the knowledge on COVID-19 disease between male and female participants ( $\mathrm{P}$-value $>0.05)$, though average knowledge score is higher among the male participants (10.45 $\pm 2.02)$ than their female counterparts $(10.38 \pm 1.27)$. Across the various age categories, marital status, education and professional, the knowledge score is showed no significant difference $(\mathrm{P}$-value $>0.05)$.

As regards to perception towards COVID-19 diseases, majority of the respondents exhibited the right perception towards the disease $331(90.4 \%)$, meaning they acknowledge the existence of the disease and are not ignorant of its transmission route. The average perception score $(27.77 \pm 3.22)$ out of a total of 35 score.

Less than $10 \%$ of the respondents neither agree nor disagree that COVID-19 is real in Nigeria 21(5.7\%). 351(95.9\%) totally support that early detection of the disease can help to improve treatment and outcome of the result. Also, majority accede that it is very important for people to disclose their recent travel history to healthcare providers, 353(96.4\%). 355(96.5) believe that the use of facemask covering the mouth and nose is very essential to prevent transmission of COVID-19 disease. More than fifty percent of the participant agreed that the use of face shield by people without the facemask is not adequate to prevent COVID-19 transmission, 189(51.6\%). At least 6 in 10 participants believe that wearing facemask and maintaining social distance is very important in curbing transmission, $227(62.1 \%)$. As shown in Appendix (table showing the relationship between socio-demographic characteristics and perception of participants towards COVID-19 disease), there is no significant difference in perception between male and female participants $(\mathrm{P}>0.05)$. The average perception score for 
male and female participants were $(28.24 \pm 3.21)$ and $(27.63 \pm$ 3.19) respectively. Across all the age categories, marital status, education and profession, the perception score showed no significant differences $(\mathrm{P}>0.05)$ Figure 1.

\section{Knowlgedge of the CBDAs on COVID-19 disease}

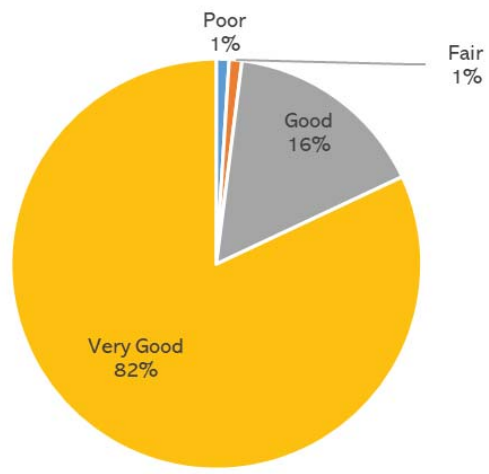

Figure 1: Knowledge of CBDAs on COVID-19 disease.

There was high compliance with use of facemask among the healthcare providers as $355(97.0 \%)$ always use facemask when attending to their clients. Majority of the clients (users of contraceptive) also showed high compliance to use of facemask when being assisted by the providers to take up DMPA-SC, $221(60.4 \%)$. As shown in Appendix, gender of participant (healthcare providers) had a significant relationship with client's compliance to use of facemask, compliance is higher among female healthcare providers $188(65.3 \%)$ than their male counterparts, $33(42.3 \%)$. This difference is significant at $95 \%$ confidence level. We also observed that compliance is also higher among healthcare providers with medical background $114(69.9 \%)$ than those without medical background, $107(52.7 \%)$, the difference is significant at $95 \%$ confidence level.

\section{Discussion}

This study assessed the knowledge and perceptions of community health providers towards COVID-19 Disease. Our respondents were community-based distributor agents working with society for family health as providers of family planning services to communities spread across the northern and southern part of Nigeria. These participants include those with medical background (CHEWs, Nurses, Doctors) and those without medical background. Majority of the participants were young adults, were females, were married and they frequently meet with women in the communities including those who have been infected but the symptoms are still asymptotic. This finding is consistent with the findings of a related study conducted by Ogolodun, et al. In Ogolodun et al. study, which was done to assess the knowledge, attitude, and fears of healthcare workers towards the corona virus disease pandemic in south-south Nigeria, reported that the most participants were within the age band of 31-40 years, $126(42.0 \%)$, female were highest $172(57.3 \%)$ and majority were married people
$203(67.7 \%)$ [10]. Our study revealed that majority of these healthcare providers are young and active to ensure continuous and consistence supply of family planning service to women in communities. Therefore, it is necessary and important that they remain healthy to effectively carry out their duties.

Majority of the respondents have a good knowledge of covid-19 pandemic in Nigeria. This finding is consistent with the findings of a related study conducted by Ogolodun, et al. on knowledge, attitude, and fears of healthcare workers towards the corona virus disease pandemic in south-south Nigeria. According to Ogolodun et al. 168(56.0\%) of the healthcare providers were highly aware and knowledgeable about covid-19 pandemic in Nigeria [10]. Our finding was also consistent with the findings from the study conducted by Wafaa Yousif Adbel Wahed et al. According to Wafaa Yousif Adbel Wahed et al. study on knowledge, attitude and perception of healthcare workers regarding covid-19 in Egypt, majority of the healthcare workers had an average knowledge score of $18.5 \pm 2.7$ out of 24 and those with correct answer rate was $80.4 \%$ [11].

The positive perception exhibited towards covid-19 was very high, that is majority of our participants acknowledged the existence of the disease and are not ignorant of all the transmission routes of the infection. This finding is similar to the findings from study conducted by Akshaya Srikanth Bhagavathula et al. According to Akshaya Srikanth Bhagavathula, et al. 288(63.6\%) of the health care workers who participated in his study on "knowledge and perception of covid-19 among HCW" exhibited positive perception towards covid-19 disease [12]. Our investigation also found out that there is a positive correlation between knowledge and perception, that is knowledge directly affected perception of people towards covid-19. The greater the community health volunteer's knowledge, the more they exhibited the right perception towards the disease.

\section{Conclusion}

The community health volunteers were very much aware and knowledgeable of the clinical presentation of COVID-19 disease, the transmission routes of the disease and its preventive measures. The study also revealed that most of these health volunteers had the right perception towards the disease, which can be attributed to the good knowledge they have about the disease. Although, we observed that a few numbers of the participants were unsure of the existence of the disease in Nigeria. This infers that, it is important to regularly conduct training on COVID-19 guidelines to keep them abreast of any latest information about the disease, eliminating any form of misconceptions and ensure adequate precaution are taken to avoid spread of the disease. Future scope of work would be to understand the fear and misconception of COVID-19 among the health volunteers.

\section{Acknowledgment}

The authors would like to thank all the DMPA-SC community-based distribution agents who agreed to participate in the survey. We thank the DMPA-SC coordinators for mobilizing the team members to participate in the survey. 


\section{Funding statement}

The authors declare that this study was conducted with funding from the Children Investment Funds Foundation (CIFF) and implemented by Society for Family Health. The content is solely the responsibility of the authors and does not necessarily represent the official views of the CIFF and SFH.

\section{References}

1. Hajra A, Bandyopadhyay D, Hajra SK (2016) Zika virus: A global threat to humanity: A comprehensive review and current developments. N Am J Med Sci 8: 123-128. Link: https://bit.ly/3o2asH9

2. Shereen MA, Khan S, Kazmi A, Bashir N, Siddique R (2020) COVID-19 infection: Origin, transmission, and characteristics of human coronaviruses. J Adv Res 24: 91-98. Link: https://bit.ly/2LciApK

3. Culp WC (2020) Coronavirus Disease 2019: In-Home Isolation Room Construction. A A Pract 14: e01218. Link: https://bit.ly/3aSdfPv

4. Bulletin N (2020) COVID-19 Outbreak in Nigeria Situation Report. NCDC.

5. Gautam R, Sharma M (2020) 2019-nCoV pandemic: A disruptive and stressful atmosphere for Indian academic fraternity. Brain Behav Immun 88: 948-949. Link: https://bit.ly/3pBpaVR

6. Olaseni AO, Akinsola OS, Agberotimi SF, Oguntayo R (2020) Psychological distress experiences of Nigerians during Covid-19 pandemic; the gender difference. Soc Sci Humanit Open 2: 100052. Link: https://bit.ly/2KF4oGf

7. Wiktorzak K, Szafraniec-Buryło S, Dziełak D, Poznerowicz I, Kułaga K, et al. (2019) Expectations towards coordinated care in Poland: patient opinion survey. Int J Integr Care 19: 654. Link: https://bit.ly/3aV66he

8. Metcalfe C (2001) Biostatistics: A Foundation for Analysis in the Health Sciences. 7th edn. Wayne W. Daniel, Wiley, 1999. No. of. pages: xiv+755+appendices. Price: 28.95 .

9. Zhong BL, Luo W, Li HM, Zhang QQ, Liu XG, et al. (2020) Knowledge, attitudes, and practices towards COVID-19 among chinese residents during the rapid rise period of the COVID-19 outbreak: A quick online cross-sectional survey. Int J Biol Sci 16: 1745-1752. Link: https://bit.ly/2X16ltm

10. Ogolodom M, Mbaba AN, Alazigha N, Erondu OF, Egbe NO, et al. (2020) Knowledge, Attitudes and Fears of HealthCare Workers towards the Corona Virus Disease (COVID-19) Pandemic in South-South, Nigeria. Heal Sci J. Link: https://bit.ly/38Nx4Vh

11. Abdel Wahed WY, Hefzy EM, Ahmed MI, Hamed NS (2020) Assessment of Knowledge, Attitudes, and Perception of Health Care Workers Regarding COVID-19, A Cross-Sectional Study from Egypt. J Community Health 45: 12421251. Link: https://bit.ly/3o4KOMZ

12. Bhagavathula SA, Aldhaleei WA, Rahmani JR, Mahabadi MA, Bandari DK (2020) Novel Coronavirus (COVID-19) Knowledge and Perceptions: A Survey of Healthcare Workers. JMIR public Heal Surveill. Link: https://bit.ly/3htxJPR
Discover a bigger Impact and Visibility of your article publication with Peertechz Publications

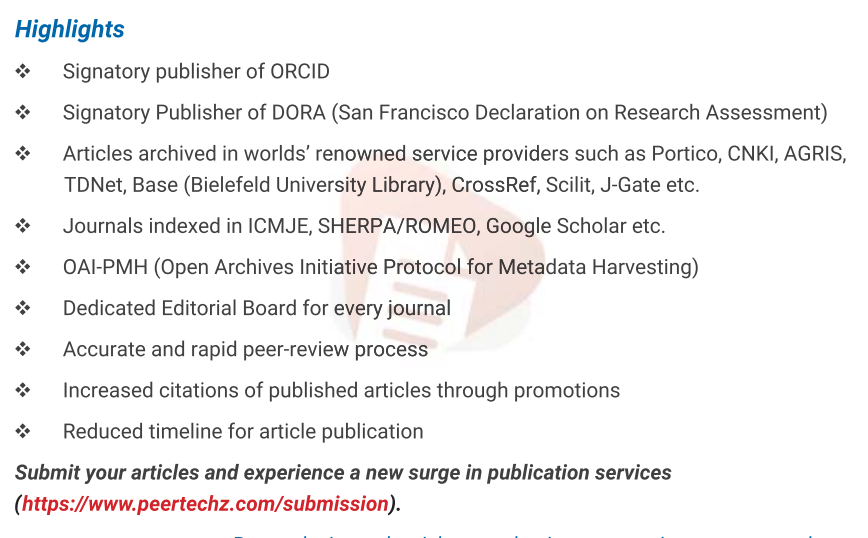

Copyright: @ 2020 Anyanti J, et al. This is an open-access article distributed under the terms of the Creative Commons Attribution License, which permits unrestricted use distribution, and reproduction in any medium, provided the original author and source are credited. 